\title{
DEVELOPMENT OF SPEED ENDURANCE, AGILITY AND BODY CONTROL IN HANDBALL USING CIRCUIT TRAINING
}

\author{
Narcis CRISTEA-MIC ${ }^{1}$, Sorin ȘIMON ${ }^{2}$, Liana Maria COSTEA ${ }^{2 *}$ \\ ${ }^{1}$ National University of Physical Education and Sport, Faculty of Physical Education and Sport, Bucharest, \\ Romania \\ 2 "1 Decembrie 1918” University, Faculty of Law and Social Science, Alba Iulia, Romania \\ *Corresponding author: costealiana2005@yahoo.com
}

https://doi.org/10.35189/dpeskj.2021.60.3.12

\begin{abstract}
The growing importance of physical preparation in the training plans of handball coaches must be the basis for consolidation and improvement during the specific training of junior handball players. The higher the motor indicators, the higher the difference between the technical and tactical skills of junior handball players in terms of achieving maximum efficiency. The research took place over an eight-month period. The research participants were 32 U17 junior handball players aged 15 and 16 years. They were divided into two groups as follows: the experimental group, consisting of 15 handball players from the Bucharest Municipal Sports Club, and the control group, consisting of 17 handball players from the Bucharest School Sports Club No. 2. The methods used for the experimental group included set training circuits performed in the corresponding part of basic training. Each training circuit was introduced systematically and quantifiably for 15 minutes, three times a week on successive days and according to the training period covered by the U17 male handball team. The training of the control group was based on traditional methods provided in the annual training plan. Throughout this period, the specific physical training parameters of the experimental group were influenced by the chosen training methods: for speed endurance in different directions and at different angles with forward, backward and lateral movements; for the ability to rotate in different directions and at different angles with an emphasis on execution speed, acceleration speed, speed endurance, agility and body control.
\end{abstract}

Keywords: male handball, circuit training, speed endurance, agility, body control.

\section{Introduction}

Professional handball remains the breeding ground for novelty and creativity. Performance has reached unforetold levels and is continuously trying to keep up with the great scientific achievements in the field. Modern handball is a dynamic and spectacular sport due to the combination of technique and endurance, reaction speed, explosive power, coordination and agility but also courage and commitment.

Handball is characterised by frequent changes in intensity, high demands on specific techniques, tactics and cognition as well as strong physical confrontations during game play. The large number of elite competitions requires players with high levels of physical performance. Therefore, physical training in the game of handball is essential for improving performance in competitions, facilitating optimal recovery between competitions and workouts and preventing injuries. (Wagner et al., 2017)

This collective game is characterised by a complexity of movements performed in changing conditions of strength and speed, which are determined by both the collaboration between teammates and the direct engagement with opponents. Modern handball involves special somatic biotypes that act at a fast pace and combine speed and strength, endurance 
and skills. In order to cope with such biological demands, the game of handball needs players with exceptional physical and mental qualities. (Hantău, 2000)

Handball is defined as "a dynamic sport in which players use their hands to dribble, pass, and shoot the ball at the opponent's goal; therefore, handball is characterized by highly developed motor skills such as coordination, speed and agility, endurance, reaction speed, as well as explosive power" (Milanese et al., 2012, p. 199).

Handball is one of the fastest team games, which requires high physical fitness levels (Karcher \& Buchheit, 2014), i.e., power, speed, agility, endurance, balance, flexibility, precision, coordination. Any handball player is a multitasker, namely a jumper, thrower and sprinter, and needs good joints to accelerate for landing, jumping and cutting manoeuvres. This game is physically demanding and intermittent in nature, requiring frequent accelerations and decelerations. (Luteberget \& Spencer, 2017)

The dynamic of today's handball game has reached a higher level that requires a higher level of players' skills in both defensive and offensive actions. "The efficient execution of simple or complex technical structures, repetitive cyclical or acyclic movements becomes an imperative that requires a high level of general motor skills and a high level of efficiency of specific motor skills." (Jovanović et al., 2020, p. 61)

Handball is a sport of intense physical contact, which is characterised by superior skills such as speed, strength, explosive power and endurance (Saeterbakken et al., 2011).

The game of handball requires all general, specific and combined motor skills: speed (reaction speed, execution speed, movement speed, combined speed); endurance (general, specific, combined); strength (general, specific, combined); coordination, which, in combination with the kinaesthetic analyser, has a role in the formation of the "flair for the ball", with the olfactory analyser - in the formation of the sense of distance, and with the auditory analyser - in the formation of balance and spatial orientation; general mobility and joint flexibility (Costea, 2017).

Players are expected to have outstanding physical qualities (speed, reactivity, strength, endurance, relaxation power) and mental qualities (ability to focus, stress resistance, good visual-motor coordination, perseverance, courage, anticipation, composure, ability to make quick decisions, efficiency in unpredictable situations, capacity for emotional and social integration in the team) (Doboși, 2009).

Speed, in all its aspects, is necessary for moving in order to perform actions faster than the opponent, which can ensure success. Three forms of speed are found in handball as follows: movement speed, reaction speed and execution speed. (Sotiriu, 1988)

The development of speed in handball is conditioned by the quality of the innate muscle fibre. This sport requires changes of direction and lateral movements that must be performed in different planes of motion. Due to this fact, athletes need to possess the ability to react to these situations with power, explosiveness and rapidity. In addition to the specific elements of each sport, agility can play a key role in predicting success in sport.

Specialists claim that agility is one of the coordination skills whose development occurs over time through many repetitions. It takes weeks and months to see a real improvement in agility. Sheppard and Young (2006) propose the following definition of agility: "a rapid whole-body movement with change of velocity or direction in response to a stimulus" ( $p$. 922). Agility has two main components, namely the change of direction and the perceptual 
and decision-making ones (Young \& Farrow, 2013; Sheppard \& Young, 2006). Agility is a crucial motor skill needed to succeed in a large number of sports but mainly in sports games.

Speed and muscle strength can be considered as critical factors of reactive agility in handball players (Horníková et al., 2021). The key to improving agility is specificity.

The characteristics of handball are the following: high intensity, body contact and wellcoordinated actions (Buchheit et al., 2009). Handball is one of the fastest sports and one of the team sports that require a high level of endurance and special manoeuvres such as jumping, shooting under pressure, faking against hard defensive players and attempting fast breakthroughs despite the fatigue (Bilge, 2013).

The morpho-functional substrate of endurance is the development stage and functional ability of the cardiovascular system, as one of the limiting factors of aerobic exercise capacity. The main organ involved in exercise is the heart, which reaches approximately $80 \%$ of its maximum volume around the age of 16 in boys, when it is possible to act intensely to develop endurance. In handball, endurance is the athletes' ability to cope in due time with the high and complex pace of the game while showing maximum efficiency, which is reflected in running, power and acyclic movement coordination (Matveev, 1991).

\section{Methodology}

\section{Participants}

The research participants were $32 \mathrm{U} 17$ junior handball players aged 15 and 16 years. They were divided into two groups as follows: the experimental group, consisting of 15 handball players from the Bucharest Municipal Sports Club, and the control group, consisting of 17 handball players from the Bucharest School Sports Club No. 2.

The research took place over an eight-month period.

To develop the research, the following equipment was used: gym benches, delimiting tape, cones and markers, stopwatch, whistle, hurdles, handballs, tape measure.

\section{Procedure}

The training of the control group was based on traditional methods provided in the annual training plan.

The methods used for the experimental group included set training circuits performed in the corresponding part of basic training. Each training circuit was introduced systematically and quantifiably for 15 minutes, three times a week on successive days and according to the training period covered by the U17 male handball team.

- Circuit Training Test (used for initial and final testing)

Aim: to test speed endurance in different directions and at different angles with forward, lateral and backward movements and the ability to rotate in different directions and at different angles with a focus on execution speed, acceleration speed, speed endurance (lower limb expansion), agility and body control

Equipment: gym bench, 26 cones, stopwatch, handball, whistle, handball goal, tape measure, adherent surface 
Working procedure:

After the whistle, from a standing start position at the starting line (a), the athlete will perform a sprint over $5 \mathrm{~m}$ to workshop 1 and, on the right side of the cone, performs a winding run through 4 longitudinally arranged cones at a distance of $1 \mathrm{~m}$ between them, always facing the direction of movement. This is followed by a $3 \mathrm{~m}$ lateral forward sprint to the right towards workshop 2 that consists of 2 longitudinal rows of cones with 3 cones each, which are placed $2 \mathrm{~m}$ apart at a depth of $1 \mathrm{~m}$ for both rows.

The athlete, starting from the right side of the first cone in the right row, will perform a lateral, winding and alternating run between the 2 rows of cones until reaching the last cone in the left row, always facing the direction of movement. Then, the athlete performs a lateral forward sprint to the right over the distance of $4 \mathrm{~m}$ towards workshop 3 that consists of 2 longitudinal rows of cones with 3 cones each, which are placed $3 \mathrm{~m}$ apart at a depth of $1 \mathrm{~m}$ for both rows.

The athlete, starting from the right side of the first cone in the right row, will perform an alternating lateral run transversely around the cones, two by two, between the 2 rows, until reaching the last cone in the right row, always facing the direction of movement. This is followed by a forward sprint over $2.2 \mathrm{~m}$ towards workshop 4, where the athlete performs successive jumps from both feet to both feet over 4 hurdles placed $0.4 \mathrm{~m}$ high and $0.8 \mathrm{~m}$ away from each other, always facing the direction of movement.

The circuit continues with a $2 \mathrm{~m}$ lateral forward sprint to the right towards workshop 5, where the athlete will perform a lateral run around the cones arranged in a transversal zigzag on 2 rows at a 3-m interval, each having 3 cones placed $2 \mathrm{~m}$ apart, always facing the handball goal.

The athlete continues with a 2 m diagonal sprint to the left towards workshop 6 , facing the goal. Here, the athlete picks up the handball with both hands from a set spot on the ground, performs a $2 \mathrm{~m}$ diagonal free dribbling to the right cone towards workshop 7. From here, the athlete continues to dribble with both hands alternately, this time in an eight shape, around 2 cones transversely placed $2 \mathrm{~m}$ away from each other, always facing the goal. The athlete continues with a $2 \mathrm{~m}$ diagonal free dribble to the right towards workshop 8 , where there are 2 cones longitudinally placed $2 \mathrm{~m}$ away from each other. Then, the athlete performs an eightshaped free dribbling around 2 cones, facing the goal at all times. This is followed by a $4 \mathrm{~m}$ free dribbling forward towards workshop 9, at the $9 \mathrm{~m}$ line (b). Here, the athlete performs an overarm jump shot without crossing the $9 \mathrm{~m}$ line (b) when taking off from the foot opposite to the shooting arm. Timing stops when the ball touches the net.

Methodological instructions:

$>$ Setting up the training circuit starts from workshop 9;

$>$ Each athlete is entitled to two attempts as warm-up;

$>$ Each athlete is timed separately, from the starting line (a) to the ball touching the net of the goal, after the overarm jump shot from the $9 \mathrm{~m}$ line (b);

$>$ Each athlete performs the test only once and the time will be recorded with an accuracy of 0.01 seconds;

$>$ The following penalty criterion will be used: 2 seconds per violation whenever the athlete deviates from the forward movement. 
Distances between workshops:

- Workshops $(1-2-3)=5+3+3+2+4+2=19 \mathrm{~m}$;

- Distance between workshops (1-2-3) and workshops (5-6-7-8-9) = $4 \mathrm{~m}$;

- Calculation: $2.20+(3 \times 0.6 \mathrm{~m}$ workshop 4$)=4 \mathrm{~m}$;

- Distance between workshops $(5,6,7,8,9): 2+5+2+2+2+2+2=17 \mathrm{~m}$;

- Total distance between workshops: $19+9+17=45 \mathrm{~m}$;

- Total distance covered by the athlete: $90 \mathrm{~m}$.

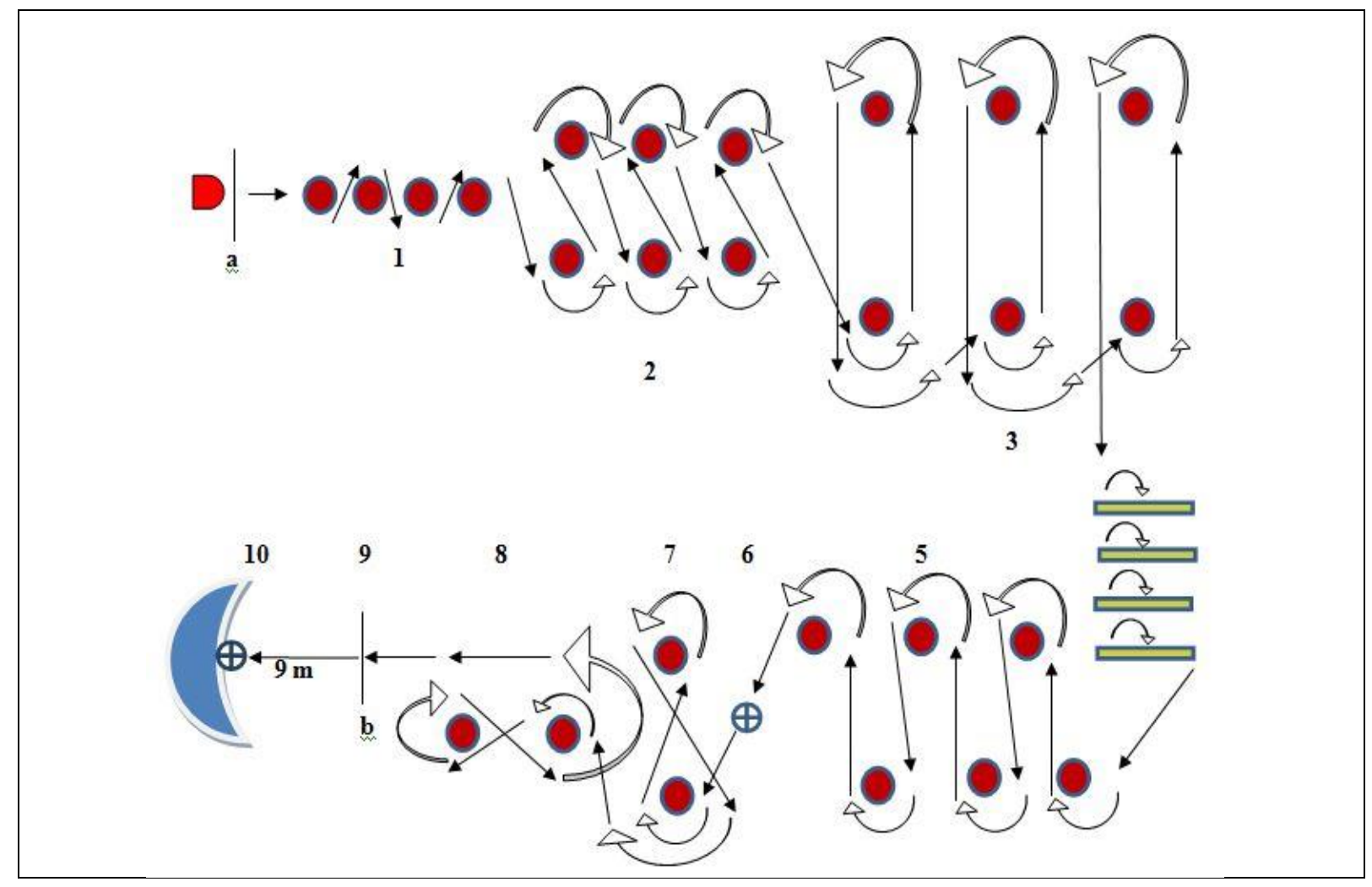

Figure 1. Circuit Training Test (used for initial and final testing) 


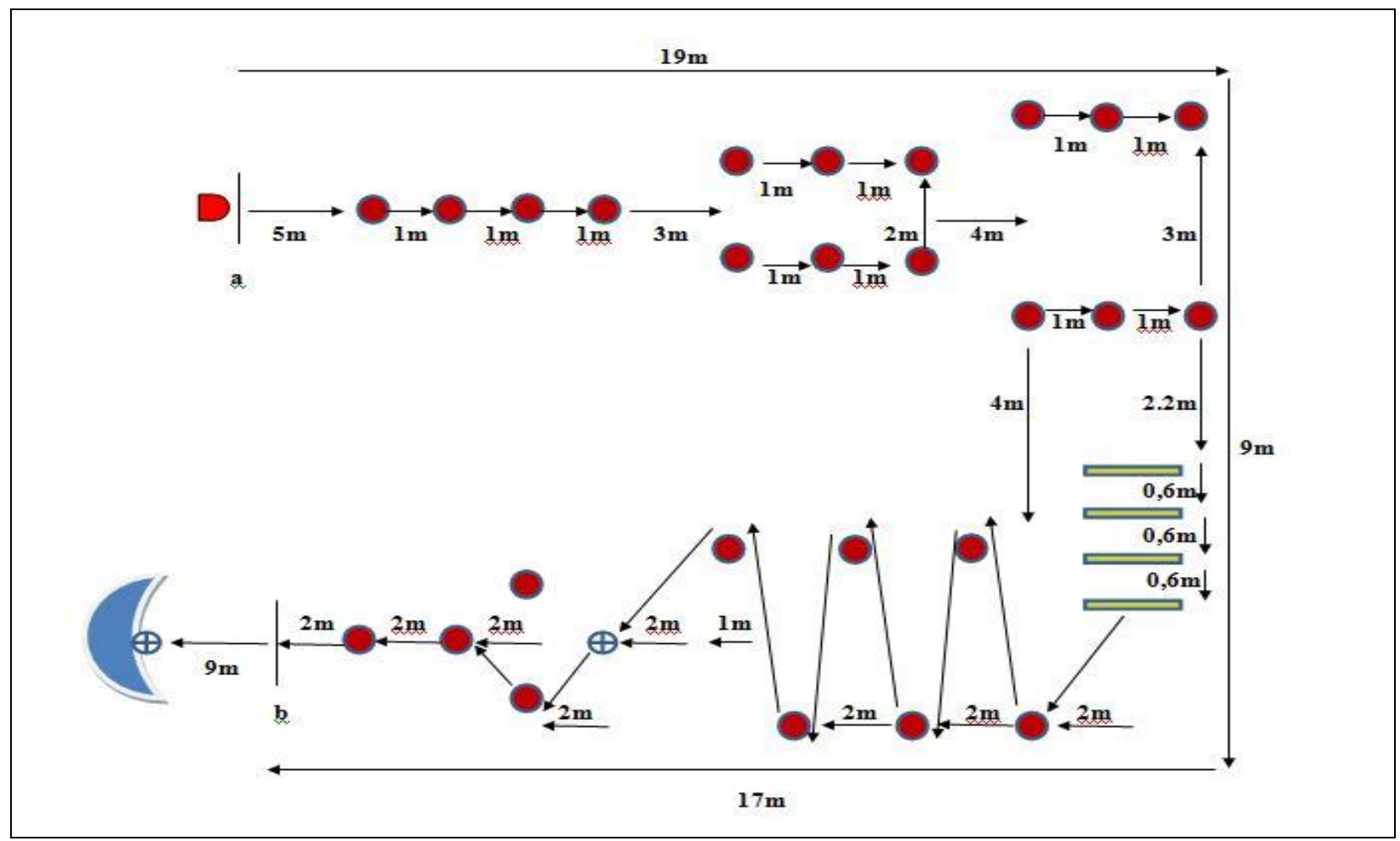

Figure 2. Circuit Training Test (used for initial and final testing)

\section{Training Circuit 1 - Exercise}

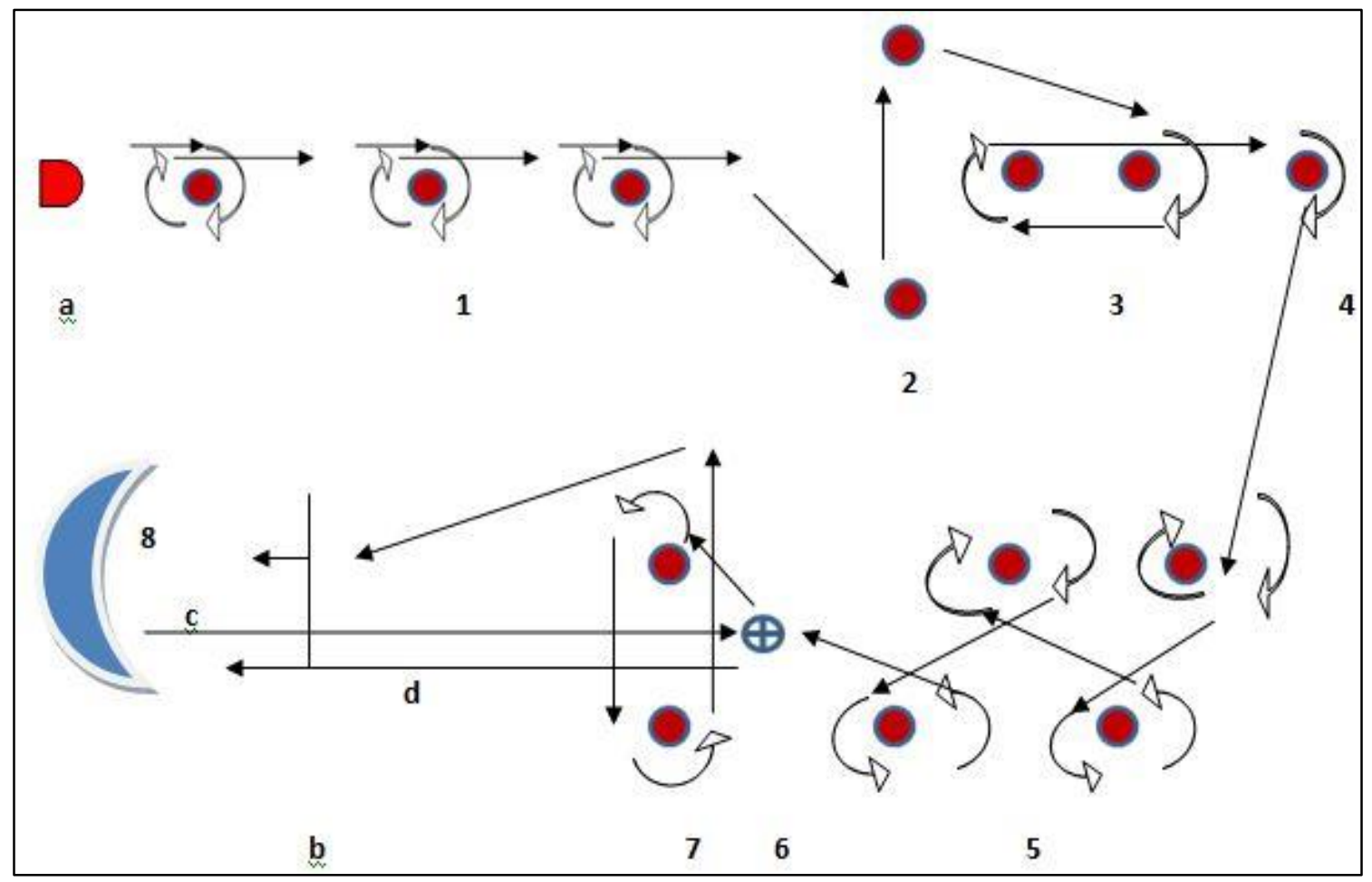

Figure 3. Training Circuit 1 - Exercise 
a. Athlete

1. Rotation around 3 cones from left to right, next time from right to left;

2. Touching the right cone with the right hand and the left cone with the left hand, lateral shuffle between the two transversely placed cones, next time in the other direction;

3. Going around the 2 cones facing forward and backward, next time in the other direction;

4. Running around a cone;

5. Rotation around 4 cones running diagonally;

6. Receiving a handball with both hands;

7. Dribbling around 2 transversely placed cones, next time in the other direction;

8. Jump shot from the $9 \mathrm{~m}$ line (b);

b. $9 \mathrm{~m}$ line;

c. Retrieving the ball from the goal and running back to workshop 6;

d. Running back into formation.

Legend:

1) The first of the three cones is $3 \mathrm{~m}$ away from the starting line, the distance between the cones being $1 \mathrm{~m}$;

2) The two transversely placed cones are $3 \mathrm{~m}$ away from workshop 1, the distance between the cones being $1 \mathrm{~m}$;

3 ) The first of the two successively placed cones is $3 \mathrm{~m}$ away from workshop (2), the distance between the cones being $4 \mathrm{~m}$;

4) Cone $10 \mathrm{~m}$ away from workshop (3);

5) 4 cones placed in a trapezium with the side of $4 \mathrm{~m}, 6 \mathrm{~m}$ away from cone (4);

6) Handball placed $4 \mathrm{~m}$ away from workshop (5);

7) 2 transversely placed cones $4 \mathrm{~m}$ away from the handball, the distance between the cones being $4 \mathrm{~m}$;

8) Jump shot from the $9 \mathrm{~m}$ line (b). 


\section{Training Circuit 2 - Exercise}

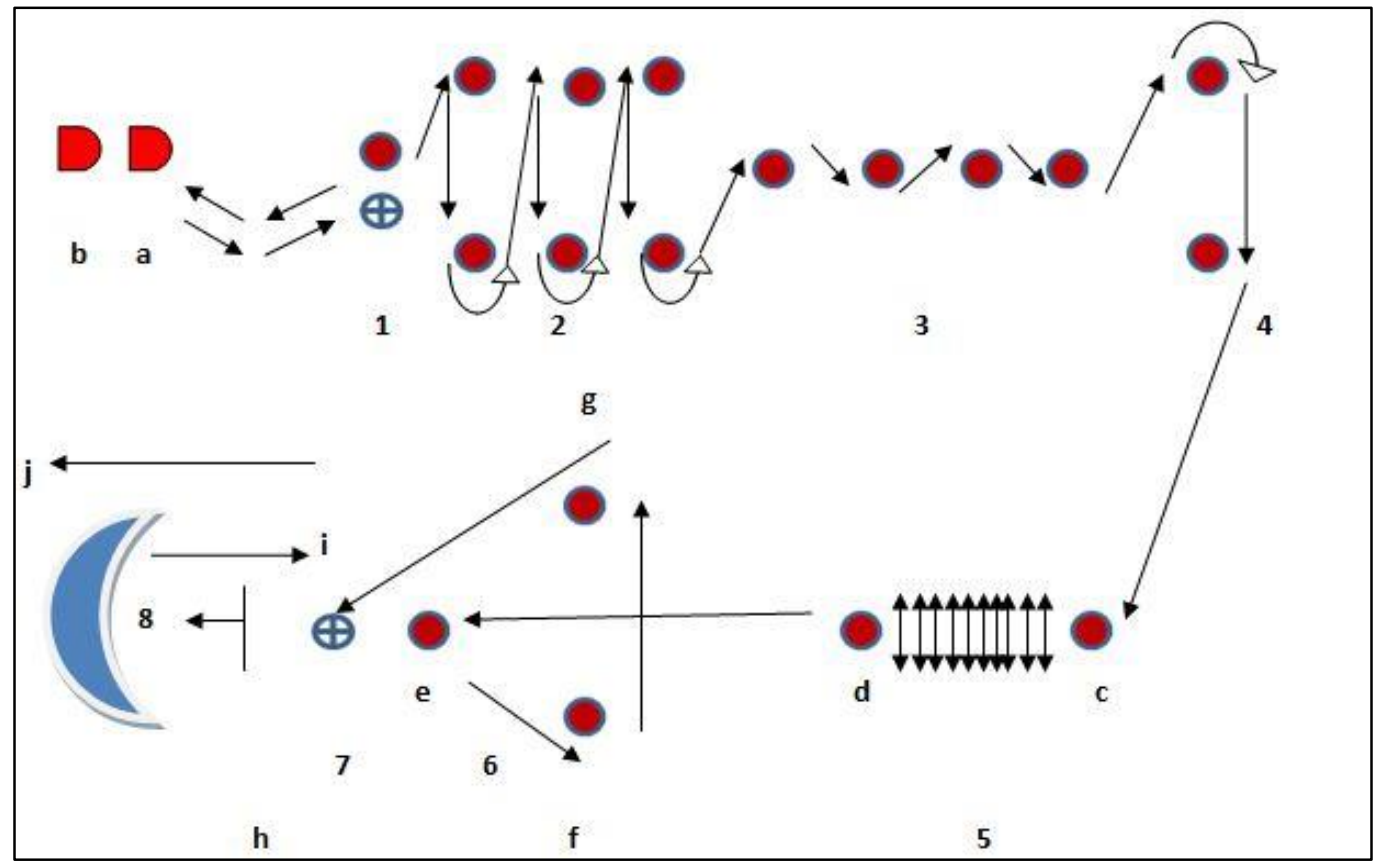

Figure 4. Training Circuit 2 - Exercise

a. Athlete one;

b. Athlete two;

1. Athlete (a) picks the ball up from the first cone and executes two bounce passes with athlete (b);

2. Lateral run and touching the left-row cones with the left hand and the right-row cones with the right hand; between the two rows, the athlete runs facing forward;

3. Winding run forward through 4 cones;

4. Running around two cones facing forward;

5. 10 left and right jumps on both feet between cones (c) and (d);

6. Running forward to cone (e), then a backward movement to cone (f), sideways running between cones ( $\mathrm{f}$ ) and $(\mathrm{g})$ forward running towards workshop (7);

7. Receiving the handball with both hands;

8. Dribbling and shooting on goal by various procedures.

h. $9 \mathrm{~m}$ line;

i. Retrieving the ball and returning to workshop (7);

j. Running back into formation.

Legend:

1) The first cone where the athlete receives the ball is $5 \mathrm{~m}$ away from the starting line;

2) 2 rows of 3 cones each, $6 \mathrm{~m}$ away from workshop (1), the distance between rows being $4 \mathrm{~m}$, the distance between cones, $3 \mathrm{~m}$;

3) 4 successively placed cones $4 \mathrm{~m}$ away from workshop (2), the distance between cones being $2 \mathrm{~m}$; 
4) 2 transversely placed cones $6 \mathrm{~m}$ away from workshop (3), the distance between the two cones being $4 \mathrm{~m}$;

5) 2 successively placed cones (c) and (d) $4 \mathrm{~m}$ away from workshop (4), the distance between the two cones being $8 \mathrm{~m}$;

6) 3 cones placed in an equilateral triangle $4 \mathrm{~m}$ away from workshop (5), the distance between cones being $6 \mathrm{~m}$;

7) Receiving a handball with both hands.

\section{Results}

- Circuit Training Test (Table 1 and Table 2)

Table 1. Experimental research - Experimental group - Initial and final testing - Circuit Training Test

\begin{tabular}{|c|c|c|c|c|}
\hline \multirow[t]{2}{*}{ No. } & \multirow[t]{2}{*}{ Year of birth } & \multirow[t]{2}{*}{ Age } & \multicolumn{2}{|c|}{$\begin{array}{c}\text { Circuit Training } 2 \text { Test } \\
\text { Unit: Seconds }\end{array}$} \\
\hline & & & Initial & Final \\
\hline 1 & 2003 & 15 & 43.18 & 40.74 \\
\hline 2 & 2002 & 16 & 43.51 & 40.79 \\
\hline 3 & 2002 & 16 & 43.77 & 41.08 \\
\hline 4 & 2002 & 16 & 44.27 & 41.29 \\
\hline 5 & 2002 & 16 & 44.32 & 41.55 \\
\hline 6 & 2002 & 16 & 44.65 & 41.68 \\
\hline 7 & 2002 & 16 & 45.12 & 41.99 \\
\hline 8 & 2003 & 15 & 45.43 & 42.28 \\
\hline 9 & 2003 & 15 & 45.66 & 42.32 \\
\hline 10 & 2003 & 15 & 45.91 & 42.56 \\
\hline 11 & 2003 & 15 & 46.14 & 42.77 \\
\hline 12 & 2003 & 15 & 46.52 & 43.01 \\
\hline 13 & 2003 & 15 & 46.89 & 43.14 \\
\hline 14 & 2002 & 16 & 47.14 & 43.29 \\
\hline 15 & 2002 & 16 & 47.69 & 43.82 \\
\hline
\end{tabular}

Table 2. Experimental research - Experimental group - Analysis of mathematical and statistical indices before and after the training programme - Circuit Training Test

\begin{tabular}{lcclcc}
\hline \multicolumn{1}{c}{ Statistical index } & IT & FT & Statistical index & FT-IT differences \\
\hline Mean & 45.35 & 42.15 & Mean & -3.19 \\
Median & 45.43 & 42.28 & Progress & $7.0 \%$ \\
Standard deviation & 1.38 & 0.95 & $95 \%$ CI & $(-3.44 ;-2.95)$ \\
Minimum & 43.2 & 40.7 & Standard deviation & 0.44 \\
Maximum & 47.7 & 43.8 & & $\mathrm{t}$ & $\mathrm{p}$ \\
Range & 4.5 & 3.1 & Dependent t-Test & 28.15 & $<0.001$ \\
Coefficient of variation & $3.1 \%$ & $2.3 \%$ & Effect size & \multicolumn{2}{c}{7.27} \\
\hline
\end{tabular}

For the experimental group, the Circuit Training Test to test speed in different directions, with an emphasis on execution speed, acceleration speed, speed strength, agility and general coordination, showed a drop of $3.19 \mathrm{sec}$ in mean execution time in the final test. The progress made is $7.0 \%$. The mean difference is within the confidence interval $(-3.44 ;-2.95)$. Variance 
is homogenous in both tests. The mean difference is very large and statistically significant, $\mathrm{p}$ $<0.001$, with $\mathrm{t}=28.15$ and $\mathrm{df}=14$. Figure 1 shows the recorded means, and Figure 2 , the individual differences between final and initial results.

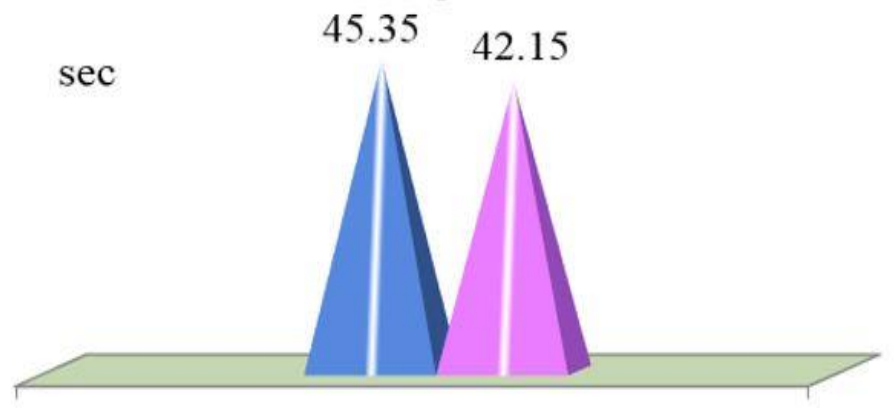

Figure 1. Experimental research - Experimental group - Initial and final testing - Mean values of individual results - Circuit Training Test

sec

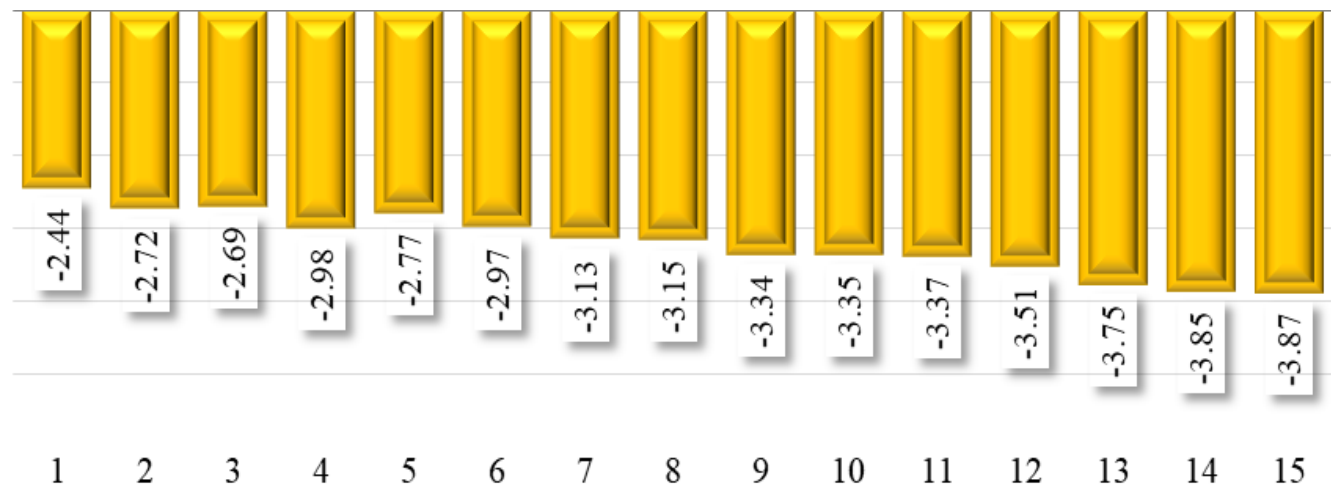

Figure 2. Experimental research - Experimental group - Initial and final testing - Differences between final and initial individual results - Circuit Training Test

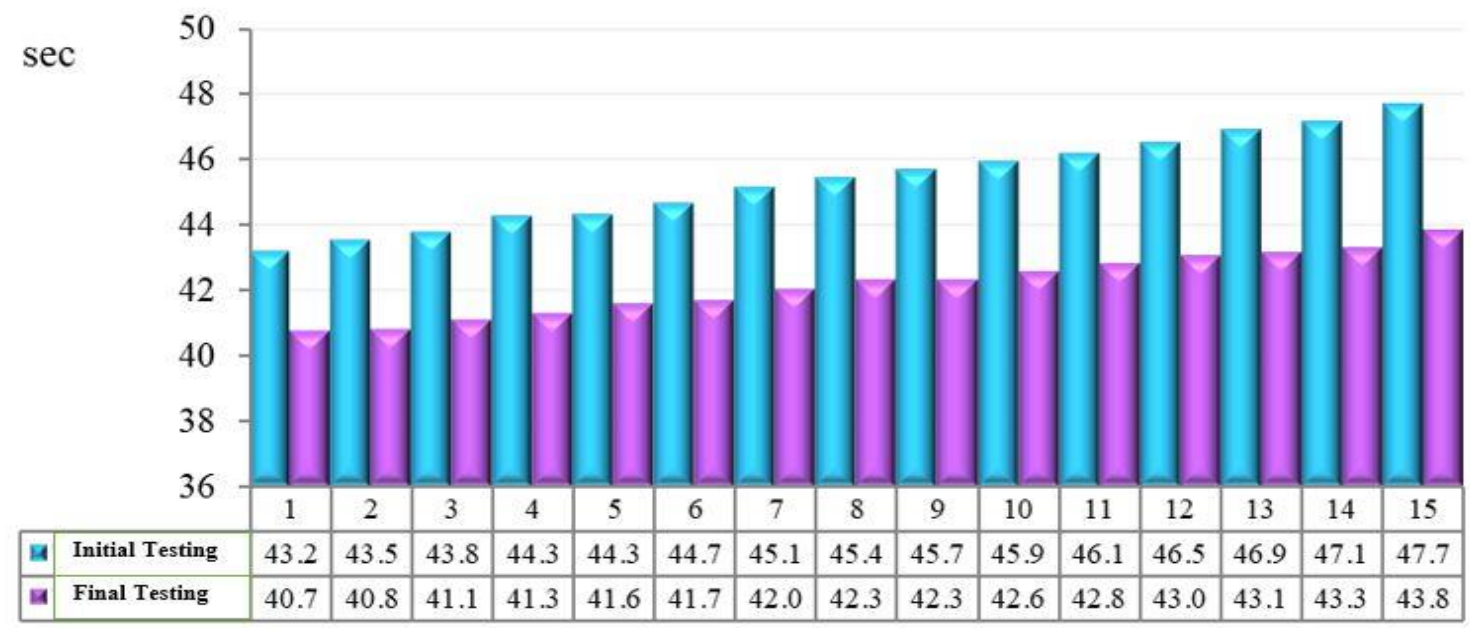

Figure 3. Experimental research - Experimental group - Initial and final testing - Final and initial individual results - Circuit Training Test 
Table 3. Experimental research - Control group - Initial and final testing - Circuit Training Test

\begin{tabular}{|c|c|c|c|c|}
\hline \multirow[t]{2}{*}{ No. } & \multirow[t]{2}{*}{ Year of birth } & \multirow[t]{2}{*}{ Age } & \multicolumn{2}{|c|}{$\begin{array}{c}\text { Circuit Training } 2 \text { Test - } \\
\text { Unit: Seconds }\end{array}$} \\
\hline & & & Initial & Final \\
\hline 1 & 2003 & 15 & 43.33 & 42.75 \\
\hline 2 & 2003 & 15 & 43.66 & 43.00 \\
\hline 3 & 2003 & 15 & 43.89 & 43.31 \\
\hline 4 & 2002 & 16 & 44.22 & 43.47 \\
\hline 5 & 2003 & 15 & 44.46 & 43.88 \\
\hline 6 & 2003 & 15 & 44.87 & 43.97 \\
\hline 7 & 2002 & 16 & 45.25 & 44.41 \\
\hline 8 & 2003 & 15 & 45.57 & 44.96 \\
\hline 9 & 2003 & 15 & 45.59 & 44.98 \\
\hline 10 & 2003 & 15 & 45.78 & 45.26 \\
\hline 11 & 2003 & 15 & 46.13 & 45.51 \\
\hline 12 & 2003 & 15 & 46.22 & 45.88 \\
\hline 13 & 2003 & 15 & 46.66 & 46.02 \\
\hline 14 & 2002 & 16 & 46.88 & 46.29 \\
\hline 15 & 2002 & 16 & 47.58 & 46.67 \\
\hline 16 & 2003 & 15 & 47.64 & 46.84 \\
\hline 17 & 2002 & 16 & 47.82 & 47.18 \\
\hline
\end{tabular}

Table 4. Experimental research - Control group - Analysis of mathematical and statistical indices before and after the training programme - Circuit Training Test

\begin{tabular}{lcclcc}
\hline \multicolumn{1}{c}{ Statistical index } & IT & FT & Statistical index & FT-IT differences \\
\hline Mean & 45.62 & 44.96 & Mean & -0.66 \\
Median & 45.59 & 44.98 & Progress & $1.4 \%$ \\
Standard deviation & 1.42 & 1.41 & 95\% CI & $(-0.73 ;-0.58)$ \\
Minimum & 43.3 & 42.8 & Standard deviation & \multicolumn{2}{c}{0.14} \\
Maximum & 47.8 & 47.2 & Dependent t-Test & t & $\mathrm{p}$ \\
Range & 4.5 & 4.4 & per & $<0.05$ \\
Coefficient of variation & $3.1 \%$ & $3.1 \%$ & Effect size & \multicolumn{2}{c}{4.55} \\
\hline
\end{tabular}

For the control group, the Circuit Training Test to test speed in different directions, with an emphasis on execution speed, acceleration speed, speed strength, agility and general coordination, showed a drop of $0.66 \mathrm{sec}$ in mean execution time in the final test. The progress made is $1.4 \%$. The mean difference is within the range $(-0.73 ;-0.58)$. Variance is homogenous in both tests. The difference between means is very large and statistically significant, $\mathrm{p}<0.05$, with $\mathrm{t}=18.76$ and $\mathrm{df}=16$. Figure 4 shows the recorded means, and Figure 5, the differences between final and initial results. 


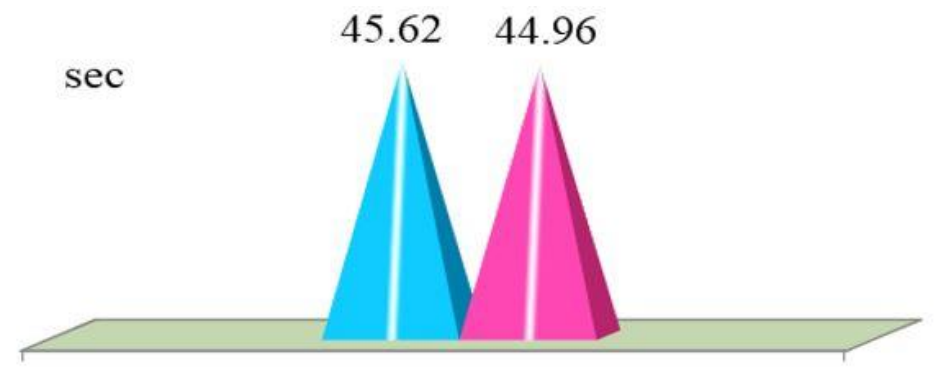

Figure 4. Experimental research - Control group - Initial and final testing - Mean values of individual results - Circuit Training Test

$\sec$

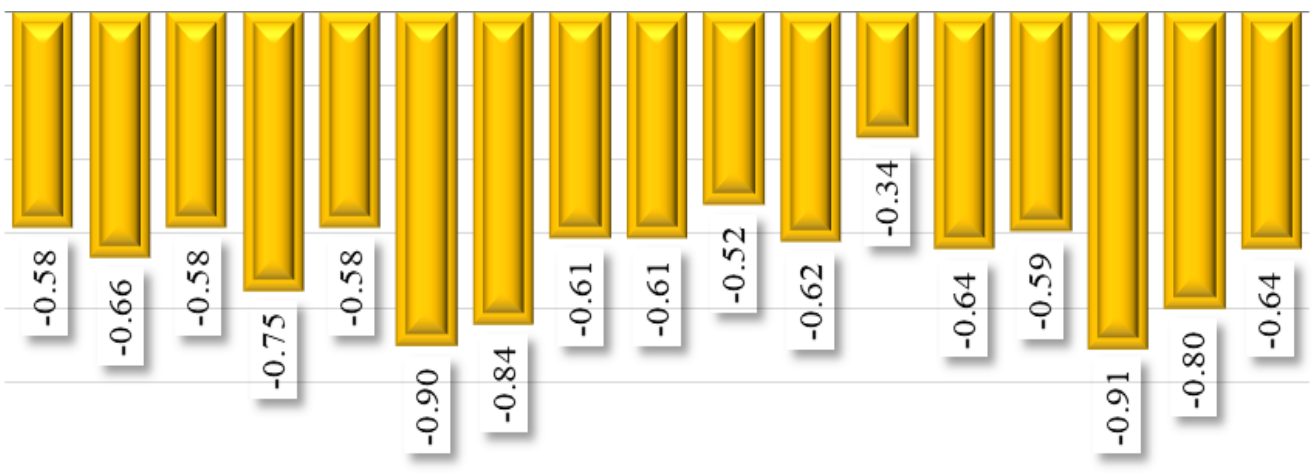

$\begin{array}{lllllllllllllllll}1 & 2 & 3 & 4 & 5 & 6 & 7 & 8 & 9 & 10 & 11 & 12 & 13 & 14 & 15 & 16 & 17\end{array}$

Figure 5. Experimental research - Control group - Initial and final testing - Differences between final and initial individual results - Circuit Training Test

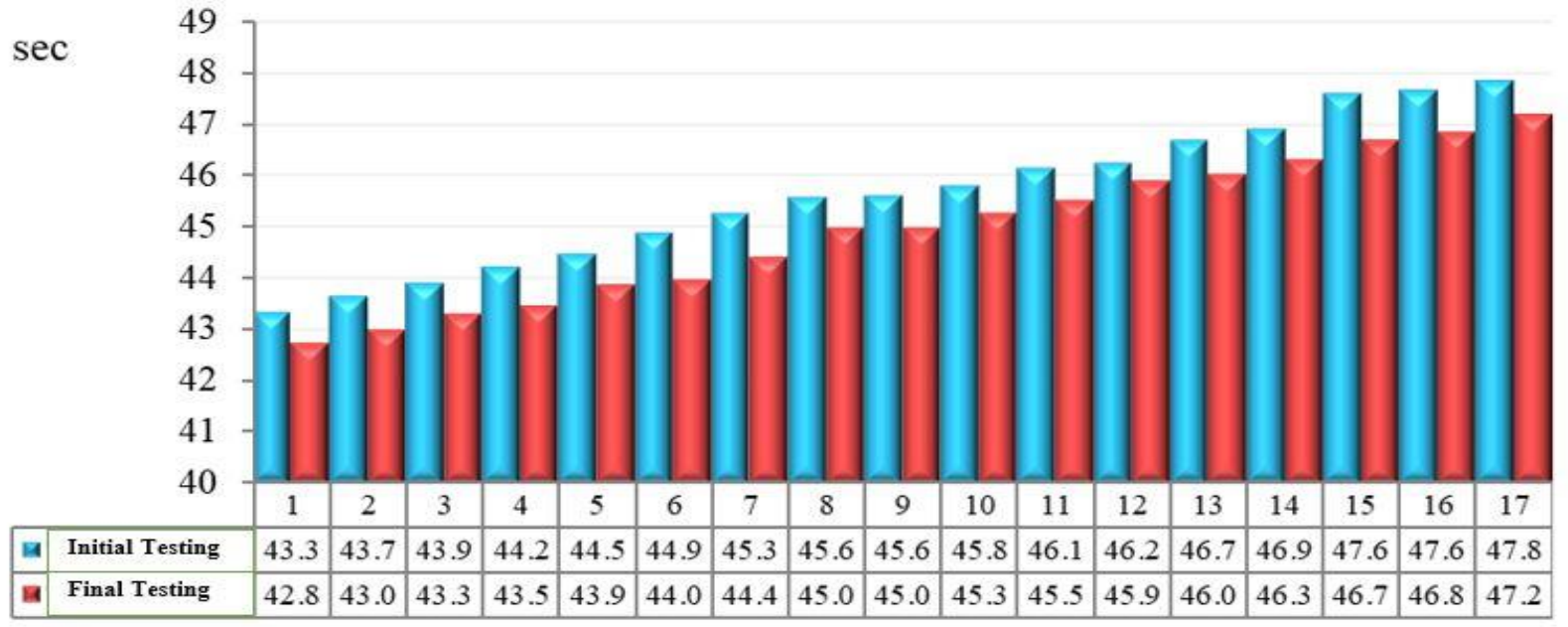

Figure 6. Experimental research - Control group - Initial and final testing - Final and initial individual results - Circuit Training Test 
Table 5. Experimental research - Experimental vs control group - Comparative analysis of mean results based on mathematical and statistical indices after the training programmeCircuit Training Test

\begin{tabular}{lcccccccc}
\hline GROUP & Mean & $\begin{array}{c}\text { Mean } \\
\text { diff. }\end{array}$ & Median & $\begin{array}{c}\text { Standard } \\
\text { deviation }\end{array}$ & Minimum & Maximum & Range & $\begin{array}{c}\text { Coeff. } \\
\text { variation }\end{array}$ \\
\hline Experimental & 42.15 & -2.81 & 42.28 & 0.95 & 40.74 & 43.82 & 3.08 & $2.3 \%$ \\
Control & 44.96 & & 44.98 & 1.41 & 42.75 & 47.18 & 4.43 & $3.1 \%$ \\
\hline
\end{tabular}

Table 6. Experimental research - Independent t-Test - Circuit Training Test

\begin{tabular}{|c|c|c|c|c|c|c|c|}
\hline \multicolumn{2}{|c|}{ Levene's Test for Equality of Variances } & \multirow{2}{*}{$\begin{array}{c}\text { Equal } \\
\text { variance }\end{array}$} & \multicolumn{4}{|c|}{ t-Test for Equality of Variance } & \multirow{2}{*}{ Effect size } \\
\hline $\mathrm{F}$ & Sig. & & Mean difference & $\mathrm{t}$ & $\mathrm{df}$ & $\mathrm{p}$ & \\
\hline 2.939 & 0.097 & YES & -2.81 & 6.521 & 30 & $<0.001$ & 2.31 \\
\hline
\end{tabular}

The independent t-Test for equality of variances, with $\mathrm{p}<0.001(<0.05)$ and $\mathrm{df}=30$, shows a statistically significant difference between the mean results recorded by the athletes of the two groups when performing the Circuit Training Test to test speed in different directions, with an emphasis on execution speed, acceleration speed, speed strength, agility and general coordination.

The mean value is $42.15 \mathrm{sec}$ for the experimental group and $44.96 \mathrm{sec}$ for the control group, which reveals that the mean of the experimental group is lower by $2.81 \mathrm{sec}(6.25 \%)$. The effect size (2.31) indicates a very large difference between the mean values of the two groups. Variance is homogenous in both tests. Figure 7 shows the corresponding mean values of athletes from both groups in the final test.

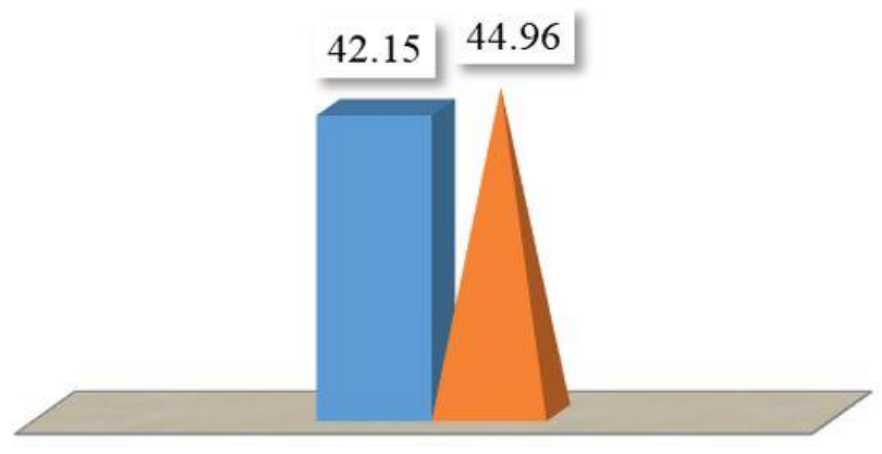

Figure 7. Experimental research - Experimental vs. control group - Mean test values - Circuit Training Test

\section{Discussion}

At this age (adolescence), the psychophysiological and neurological processes become stable and help growth and the alactacid anaerobic effort is well tolerated, which is why the training programme is based on exercises aimed at developing repetition speed, execution speed, movement speed, speed endurance and less on pure speed. 
Interval training is one of the most common methods used in handball because, when properly designed, it can induce specific metabolic demands and match the physiological profile of the game of handball. Furthermore, training lessons can be conducted on the field to increase specificity and can be adjusted according to the requirements of playing positions and individual abilities of players (Iacono et al., 2018).

It is the period when coordination ability is significantly improved and has visible effects on skill level. At this stage, the chance of formation, consolidation and improvement of motor skills and abilities is higher, regardless of their degree of complexity and difficulty. This is due to the advanced stage of physical and mental development, the high degree of motor qualities and a solid metabolic support.

Improving agility requires a number of specific skills that need to be addressed in order to create a training programme that aims to improve these essential components. It should be included in the annual training programme as a core component, giving athletes the opportunity to apply the benefits of strength development and fitness programmes during competitions.

When athletes use agility exercises, they develop neuromuscular awareness and are therefore better able to understand their own body movements.

This motor skill and ability content is supplemented by new technical procedures with qualitative performance indices and specific tactical actions, whose proportion is established individually depending on the situation, the level of training and age.

It is essential that youth players are given the necessary training to enable them to undertake proper physical development at an early age. This would improve players' ability to complete full strength and speed training programmes needed to meet the requirements of senior elite handball. This would also add to the total number of training hours, thus increasing the chances of developing sufficient physical abilities to reach the level of senior handball (Ingebrigtsen et al., 2017).

Identifying talented children, assessing their strengths and weaknesses, assigning team positions and properly planning training programmes are fundamental elements. Thus, understanding the body composition of athletes and then assigning corresponding competitive weights for them has been done for decades and is considered an essential part of the total management process (Wilmore, 1982).

\section{Conclusion}

The technical elements of the game of handball, such as movement on the field, holding the ball or passing, driving or dribbling it, shooting through various handball-specific technical procedures, are combined during training circuits with methods for the development of lower limb expansion, movement speed, repetition speed and execution speed. Their main objective is to increase agility, coordination, multidirectional control and to stimulate creativity, implicitly improving the individual technique of male U17 handball players, with or without the ball.

The diversity of materials used in this physical training programme aimed to modernise and diversify the training process in order to capture attention while motivating athletes. The variety of methods included in the programme improved the training of male U17 handball 
players by increasing the specific indices of speed endurance (in all its aspects), coordination, agility, orientation and body control.

Beyond all this theory, we wish the results of this study to be the starting point in setting up physical training programmes that include circuit training methods.

We recommend the introduction of complex motor structures at this age, puberty being characterised by a stabilisation of the ability to acquire new motor structures, which leads to a rapid increase in performance and the quality of the acquired technical and tactical elements.

\section{References}

Bilge, M. (2013). Interval training specific to handball and training programme designs. World Applied Sciences Journal, 25(7), 1066-1077.

DOI: 10.5829/idosi.wasj.2013.25.07.13363

Buchheit, M., Lepretre, P. M., Behaegel, A. L., Millet, G. P., \& Ahmaidi. S. (2009). Cardiorespiratory responses during running and sport-specific exercises in handball players. Journal of Science and Medicine in Sport, 12(3), 399-405. https://doi.org/10.1016/j.jsams.2007.11.007

Costea, L. M. (2017). Particularitățile psiho-motrice ale jucătoarelor liniei de 6 m junioare II [Psycho-motor characteristics of 6-m line junior II female players]. Universitaria.

Doboşi, Ş. (2009). Refacerea şi recuperarea după efortul din antrenament și competiție [Recovery and regeneration after training and competition effort]. Napoca Star.

Hantău, C. (2000). Handball [Handball]. Alphina.

Horníková, H., Jele, M., \& Zemková, E. (2021). Determinants of reactive agility in tests with different demands on sensory and motor components in handball players. Applied Sciences, 11(14): 6531. https://doi.org/10.3390/app11146531

Iacono, A. D., Karcher, C., \& Michalsik, L. B. (2018). Physical training in team handball. In L. Laver, P. Landreau, R. Seil, \& N. Popovic (Eds.), Handball sports medicine (pp. 521535). Springer Berlin Heidelberg.

Ingebrigtsen, J., Jeffreys, I., \& Rodahl, S. (2017). Physical characteristics and abilities of junior elite male and female handball players. The Journal of Strength and Conditioning Research, 27(2), 302-309. https://doi.org/10.1519/jsc.0b013e318254899f

Jovanović, S., Marković, S., \& Ilić, N. (2020). Relationships of motor abilities and precision of shooting in handball. Sports Science and Health, 19(1), 60-66.

https://doi.org/10.7251/SSH2001060J

Karcher, C., \& Buchheit, M. (2014). On-court demands of elite handball, with special reference to playing positions. Sports Medicine, 44(6), 797-814. https://doi.org/10.1007/s40279-014-0164-z

Luteberget, L. S., \& Spencer, M. (2017). High-intensity events in international women's team handball matches. International Journal of Sports Physiology and Performance, 12(1), 5661. https://doi.org/10.1123/ijspp.2015-0641

Matveev, L. P. (1991). Antrenamentul și organizarea acestuia [Training and its organization]. Revista Sportul de Performanță, 311, 15-30.

Milanese, C., Piscitelli, F., Lampis, C., \& Zancanaro, C. (2012). Effect of competitive season on anthropometry and body composition in female handball players. Biology of Sport, 29(3), 199-204. DOI: 10.5604/20831862.1003443

Saeterbakken, A. H., van den Tillaar, R., \& Seiler, S. (2011). Effect of core stability training on throwing velocity in women's handball players. The Journal of Strength \& Conditioning Research, 25(3), 712-718. DOI: 10.1519/JSC.0b013e3181cc227e 
Sheppard, J. M., \& Young, W. B. (2006). Agility literature review: Classifications, training and testing. Journal of Sports Sciences, 24(9), 919-932. https://doi.org/10.1080/02640410500457109

Sotiriu, R. (1998). Handbal. Antrenament. Teorie și metodică [Handball. Training. Theory and methodology]. Garold.

Wagner, H., Gierlinger, M., Adzamija, N., Samuelajayi, S., Bacharach, D. W., \& Von Duvillard, S. P. (2017). Specific physical training in elite male team handball. The Journal of Strength and Conditioning Research, 31(11), 1-11. https://doi.org/10.1519/jsc.0000000000002094

Wilmore, J. H. (1982). Body composition and athletic performance. In W. Haskell, J. Scala, \& J. Whittam (Eds.), Nutrition and athletic performance (pp. 158-75). Bull Publishing.

Young, W., \& Farrow, D. (2013). The importance of a sport-specific stimulus for training agility. Strength \& Conditioning Journal, 35(2), 39-43.

DOI: $10.1519 / \mathrm{SSC} .0 \mathrm{~b} 013 \mathrm{e} 31828 \mathrm{~b} 6654$ 